\title{
GT2019-91413
}

\section{CONTROL TECHNOLOGY NEEDS FOR ELECTRIFIED AIRCRAFT PROPULSION SYSTEMS}

\author{
Donald L. Simon \\ NASA Glenn Research Center \\ Cleveland, $\mathrm{OH}, \mathrm{USA}$
}

\author{
Joseph W. Connolly \\ NASA Glenn Research Center \\ Cleveland, $\mathrm{OH}$, USA
}

\author{
Dennis E. Culley \\ NASA Glenn Research Center \\ Cleveland, $\mathrm{OH}, \mathrm{USA}$
}

\begin{abstract}
Electrified aircraft propulsion (EAP) systems hold potential for the reduction of aircraft fuel burn, emissions, and noise. Currently, NASA and other organizations are actively working to identify and mature technologies necessary to bring EAP designs to reality. This paper specifically focuses on the envisioned control technology challenges associated with EAP designs that include gas turbine technology. Topics discussed include analytical tools for the dynamic modeling and analysis of EAP systems, and control design strategies at the propulsion and component levels. This includes integrated supervisory control facilitating the coordinated operation of turbine and electrical components, control strategies that seek to minimize fuel consumption and lessen the challenges associated with thermal management, and dynamic control to ensure engine operability during system transients. These dynamic control strategies include innovative control approaches that either extract or supply power to engine shafts dependent upon operating phase, which may improve performance and reduced gas turbine engine weight. Finally, a discussion of control architecture design considerations to help alleviate the propulsion/aircraft integration and certification challenges associated with EAP systems is provided.
\end{abstract}

\section{INTRODUCTION}

Since the dawn of aviation, fossil fuel burning engines have served as the dominant source of aircraft propulsive thrust. However, recent technological advances in batteries and electrical systems have enabled the exploration of alternative designs that rely on the generation, storage, and transmission of electrical power for aircraft propulsion. The motivation to consider electrified aircraft propulsion (EAP) designs is being driven by aviation fuel burn, emission, noise, and cost reduction goals $[1,2]$. EAP offers flexibility in storing and transmitting electrical power, which enables aircraft designs that apply advanced propulsion concepts such as distributed electric propulsion and boundary layer ingestion fans. EAP systems take the form of several potential architectures as shown in Figure 1 $[3,4]$. These EAP architecture options include:

- All electric: Batteries provide the sole source of propulsive power.

- Hybrid electric: A combination of batteries and combustion engines provide propulsive power. In parallel hybrid designs, a battery-powered motor and a turbine engine are both mounted on a shaft that drives a fan, so that either or both can provide propulsion. In series hybrid designs, only the electric motors are mechanically connected to the fans; the gas turbine drives an electrical generator, which produces power to drive the motors and/or charge batteries.

- Turboelectric: Combustion engines provide propulsive power with all (full turboelectric) or some (partial turboelectric) of the engine power output converted to electricity.

- Series/parallel partial hybrid system: Has one or more fans that can be driven directly by a gas turbine as well as other fans that are driven exclusively by electrical motors. These motors can be powered by a battery or by a turbine-driven generator.

The NASA Aeronautics Research Mission Directorate strategic implementation plan outlines a vision to transition to alternative propulsion and energy sources [5]. This includes a range of electrified propulsion solutions including all-electric, turboelectric, and hybrid electric designs. Several electrified aircraft concept vehicles have been proposed by NASA as shown in Figure 2. This includes fixed-wing aircraft design concepts such as the all-electric X-57 Maxwell [6], the Single-aisle Turboelectric AiRCraft with $\underline{\text { Aft }}$ Boundary Layer propulsor (STARC-ABL) [7], and the NX-3 blended wing body with distributed turboelectric propulsion [8]. Also shown are electrified rotorcraft vehicles proposed under NASA's Revolutionary Vertical Lift Technology Project $[9,10]$. 

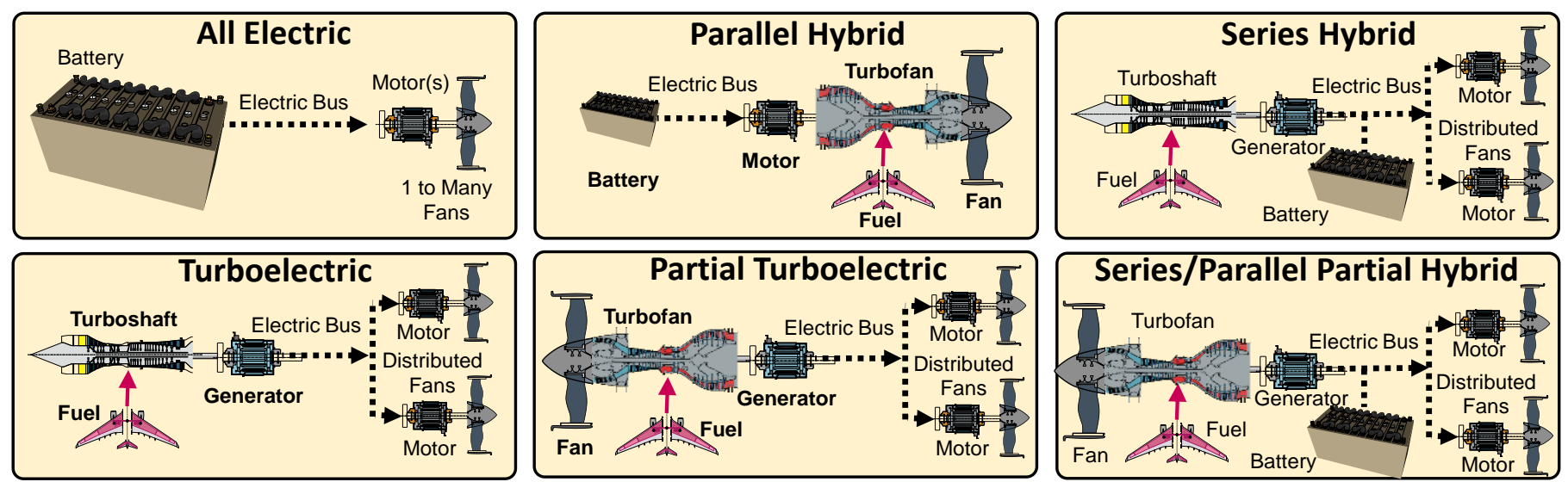

Figure 1. Electrified aircraft propulsion architectures (from Refs. [3,4])

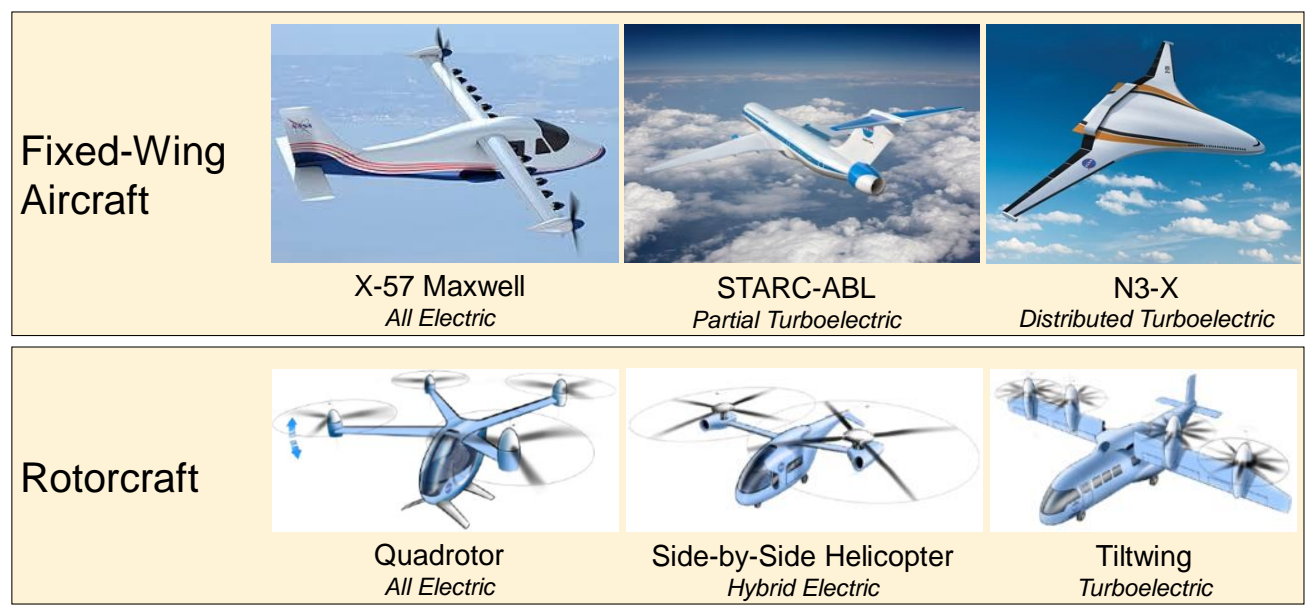

Figure 2. NASA electrified aircraft concept vehicles (from Refs. [6-10])

A multitude of EAP vehicle concepts are also being explored in industry. Almost 100 electrically propelled aircraft are in development worldwide [11]. These are mostly all-electric designs targeting the general aviation and urban air mobility markets. EAP targeting larger commercial aircraft tend to be turboelectric or hybrid electric designs. Examples include the E-Fan X series hybrid propulsion aircraft being developed by Airbus in partnership with Rolls-Royce and Siemens [12] and Zunum Aero's regional airliner with hybrid electric propulsion [13].

Multiple technology advances are required to enable EAP implementation on next generation aircraft [4]. This includes improvements in electrical motors and generators to achieve higher efficiency and specific power, technology to enable increased battery specific energy, and power electronics and power distribution system technology to enable operation at higher voltage levels at altitude. Advances in gas turbine technology are needed to enable high levels of engine power extraction or power addition. Another significant challenge is thermal management of the EAP system.

In addition to the technology challenges noted above, EAP also presents significant controls-related challenges. This includes development of the control design tools and strategies to ensure reliable and efficient operation of EAP systems, both under normal and anomalous operating scenarios. This paper will specifically focus on the control technology challenges associated with the design and operation of EAP designs that include gas turbine technology. Several of these challenges were identified by the Commercial Aero-Propulsion Controls Working Group (CAPCWG), a consortium of NASA and United States engine and aircraft manufacturers focused on identifying propulsion control and related technology development needs that are aligned with NASA's Aeronautics Mission Directorate Programs and Projects. The EAP control technology needs identified by CAPCWG in Ref. [14] are further expanded upon and discussed in this document.

The remaining sections of this paper are organized as follows. First, a comparison between the control architectures required for conventional aircraft engines versus EAP designs is given. This is followed by a discussion of the modeling and control design tools needed for developing EAP control systems. Next, EAP control strategies are discussed. This includes a discussion of the integrated control strategies required for coordinated operation of turbine and electrical components, and 
the potential control enhancements offered by the flexible nature of EAP designs. The paper then provides a discussion of the test facilities required for EAP evaluation and maturation. The paper concludes with a discussion of the control considerations related to the certification of EAP systems along with a summary.

\section{NOMENCLATURE}

$\begin{array}{ll}\text { AC } & \text { Alternating current } \\ \text { CAPCWG } & \text { Commercial aero-propulsion controls working } \\ \text { group } & \text { Contingency power } \\ \text { DAL } & \text { Development assurance level } \\ \text { DC } & \text { Direct current } \\ \text { EAP } & \text { Electrified aircraft propulsion } \\ \text { ECS } & \text { Environmental control system } \\ \text { EEC } & \text { Electronic engine control } \\ \text { FHA } & \text { Functional hazard assessment } \\ \text { HEIST } & \text { Hybrid electric integrated systems testbed } \\ \text { HIL } & \text { Hardware-in-the-loop } \\ \text { HPC } & \text { High pressure compressor } \\ \text { HPT } & \text { High pressure turbine } \\ \text { IFPC } & \text { Integrated flight and propulsion control } \\ \text { LPC } & \text { Low pressure compressor } \\ \text { LPT } & \text { Low pressure turbine } \\ \text { MCP } & \text { Maximum continuous power } \\ \text { MP } & \text { Maximum power } \\ \text { NEAT } & \text { NASA electrified aircraft testbed } \\ \text { NPSS } & \text { Numerical propulsion system simulation } \\ \text { MEE } & \text { More electric engine } \\ \text { PLA } & \text { Power lever angle } \\ \text { PROOSIS } & \text { Propulsion object-oriented simulation software } \\ \text { SFC } & \text { Specific fuel consumption } \\ \text { STARC-ABL } & \text { Single-aisle turboelectric aircraft with aft } \\ \text { TEEM } & \text { boundary layer propulsor } \\ \text { TLD } & \text { Turbine electrified energy management } \\ \text { T-MATS } & \text { Time-limited-dispatch } \\ & \text { Toolbox for the modeling and analysis of } \\ \text { thermodynamic systems } \\ \end{array}$

\section{COMPARISON OF CONVENTIONAL VERSUS EAP CONTROL ARCHITECTURES}

An aircraft engine's control system plays a vital role in ensuring the safe, reliable, and efficient operation of the engine throughout the aircraft's operating envelope, which includes controlling the engine during transient operation. A comparison between a conventional aircraft propulsion control architecture and an EAP control architecture is shown in Figure 3. These two architectures will be further discussed in the paragraphs below.

In the conventional aircraft engine control architecture shown in Figure 3a, communication between the aircraft and each engine installed on the vehicle occurs through an Electronic Engine Control (EEC) computer. The EEC is a dual-channel computer that receives thrust demands along with power and bleed offtake requests from the aircraft. These aircraft requests, along with engine sensed feedback measurements, are processed by control logic implemented within the EEC and used to calculate control commands sent to actuators installed on the engine. Fuel flow rate is the primary parameter adjusted to control engine thrust or torque output. Since engine thrust output cannot be sensed directly, a feedback measurement correlated to thrust, such as fan speed or engine pressure ratio, is used to establish a closed-loop fuel control design. Additional engine actuators such as variable guide vanes and bleed valves are open-loop scheduled by the EEC to ensure engine operability. The EEC supplies engine parameters back to the aircraft for cockpit gauge displays and health and status information purposes.

Engine control systems must be robust to account for engine-to-engine performance variations that naturally exist. Limit logic is applied to ensure that the engine does not encounter operability issues such as surge or combustor blowout, and that structural and temperature limits are not exceeded. Additionally, the engine control plays an important function in engine fault detection, isolation, and accommodation. This includes logic to diagnose and accommodate faults. Accommodation actions may include switching to physically redundant hardware (e.g., computer channel, sensor, or actuator), commanding actuators to failsafe positions, or switching to revisionary control modes in the event of a fault. The conventional engine control architecture tends to be centralized in its design, and the controller is certified along with the engine.

EAP control architectures are application dependent, but in general EAP control systems are expected to be more distributed and more complex than their conventional engine control counterparts. A notional EAP control architecture for a hybrid electric propulsion system is shown in Figure 3b. Here, propulsive thrust is generated by gas turbine engines and an array of distributed electrically driven fans. Electrical components, including generators, batteries, power electronics, electrical buses and motors, are included to enable the generation and delivery of electrical power to the distributed fans. EEC units control the operation of the gas turbines, while an electronic component controller regulates the operation of the generators, battery, and distributed electrical motor driven fans. A supervisory controller is included to control operation of the turbine and electrical subsystems, and it also serves as the communication interface between the aircraft and the propulsion system. Given the coupling between turbine and electrical system operation, the supervisory controller plays a vital role in coordinating the operation of both subsystems to optimize efficiency, reduce thermal management challenges, and maintain overall operating limits. As with the conventional engine control architectures, the EAP design must be robust to performance variations and system faults. Due to their diversity of components and coupled nature, EAP systems are expected to present more failure modes and also enable new system reconfiguration options in response to faults. As such, fault detection and accommodation logic embedded within the control system is expected to play a vital role in supporting EAP system certification requirements. 


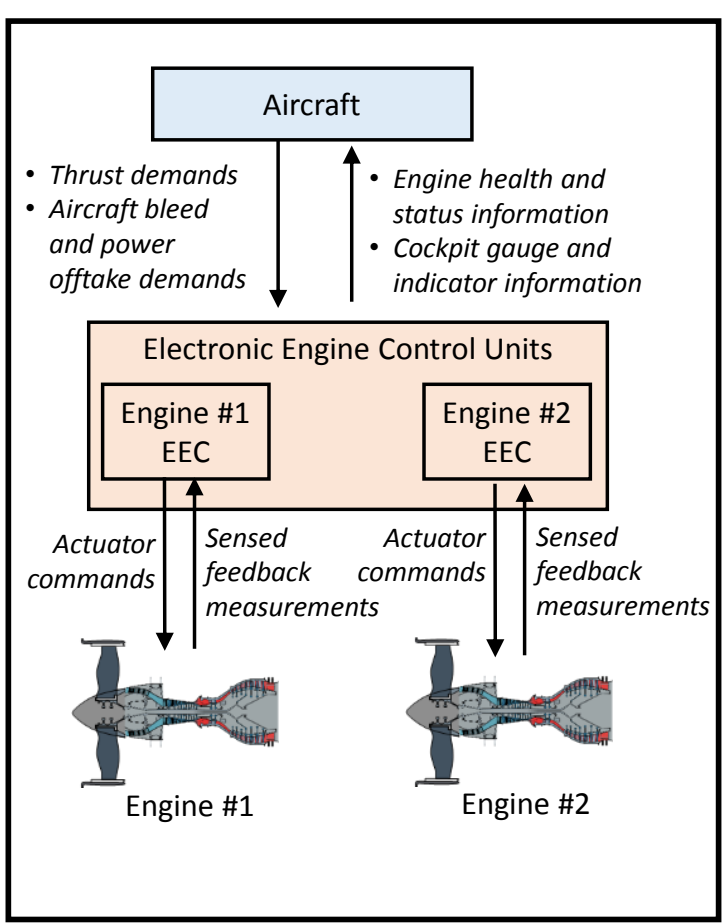

a) Conventional aircraft propulsion control architecture control architecture
Figure 3. Comparison of conventional and electrified aircraft propulsion control

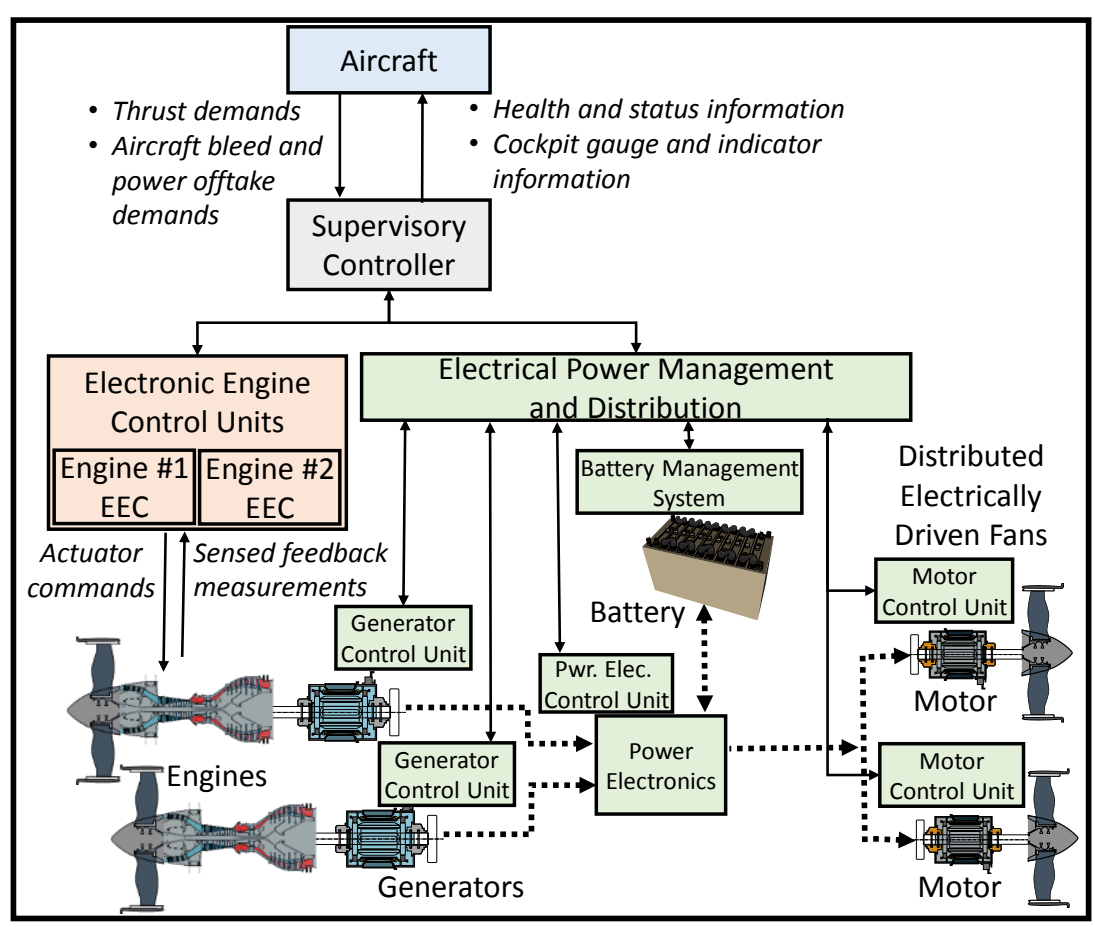

b) Electrified aircraft propulsion

\section{AIRCRAFT ENGINE CONTROLS DEVELOPMENT PROCESS AND APPLIED TOOLS}

A high-level illustration of the aircraft engine controls development process and applied tools is shown in Figure 4. Here, a series of maturation steps are shown, each of increasing cost and complexity. Often, development iterations are needed to make control system updates. The process begins by receiving information on the propulsion system design concept. This is typically obtained through system studies conducted to design and size the propulsion system to match its intended aircraft mission. Given the propulsion system design concept, the control development process includes the steps of dynamic modeling, control design, real-time simulation and hardware-in-the-loop (HIL) evaluation, engine testing, and flight testing. Certification considerations are applied throughout this process to ensure that the design complies with the airworthiness standards set forth by regulatory agencies. The upcoming sections will discuss the tools, control design strategies, facilities, and certification considerations related to EAP control system development.

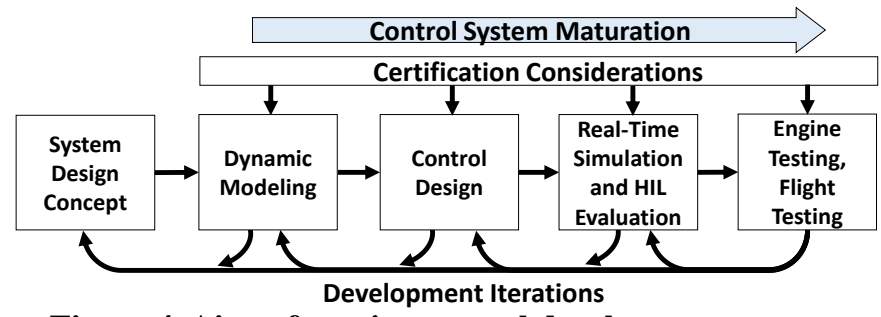

Figure 4. Aircraft engine control development process

\section{MODELING AND CONTROL DESIGN TOOLS}

Dynamic system modeling and computational analysis tools are integral to the aircraft engine control development process. During the development cycle of an engine, a non-linear physicsbased model of the engine is created and used to design turbomachinery and evaluate system-level performance. Such models are complex, capturing the behavior and coupling of all engine components including the inlet, fan, compressors, combustor, turbine, and exhaust nozzle. Other design aspects of the engine such as bypass ducts, cooling flows, bleed and mechanical power offtakes, and variable guide vanes are also represented in these models.

The models may be either steady-state or dynamic, with steady-state models capturing the "on-design" performance of the engine and dynamic models enabling simulation of the "offdesign" performance encountered by the engine during transients. Dynamic models are necessary for the design of engine control systems, which are tasked with ensuring the safe and reliable transient operation of the engine in response to varying thrust requests and flight conditions. The dynamics captured by these models are typically in the 10's of Hz range, set by conventional fuel and variable geometry actuation systems and the dominant spool inertias transient response. Higher frequency dynamics such as blade flutter, compressor stall, or combustion instabilities are typically not included in the models used for control design, although the operating limits where these instabilities are expected to be encountered should be defined in the models. 
Various modeling tools are available for constructing gas turbine engine models, such as the Numerical Propulsion System Simulation (NPSS) [15], GasTurb [16], Propulsion ObjectOriented Simulation Software (PROOSIS) [17], and the Toolbox for the Modeling and Analysis of Thermodynamic Systems (T-MATS) [18]. Enhancements to these tools are necessary to enable modeling of the electric machines, energy storage devices, and power management and distribution hardware found in EAP concepts. These enhanced modeling tools should also enable modeling of the relevant dynamic interaction between electrical and mechanical components, as well as the effects of modulating available actuators. Additionally, these tools should model sources of heat generation and dissipation within the system for thermal management considerations.

Tools are also needed to develop models representative of off-nominal EAP system behavior. Simulating component performance variations due to variations in environmental conditions, manufacturing tolerances or normal deterioration that components are expected to experience over their lifetime of use will allow control robustness to be assessed. Additionally, the simulation of EAP system faults will allow initial development and evaluation of fault detection, isolation, and accommodation logic, including the logic required to mitigate functional hazards and enable certification.

Most aircraft engine control designs are based on linear control approaches. As such, tools for the automated generation of linear state-space models based on non-linear models are needed. These linear state-space models should be extractable at multiple operating points spanning the EAP system's operating envelope, allowing them to be coupled together in a piecewise linear fashion [19]. Real-time code generation capabilities are also desired to support real-time simulation and hardware-in-theloop evaluation of control systems (see Figure 4). Control design tools to coordinate operation of the turbine and electrical subsystems will also be beneficial.

Challenges include modeling EAP systems to the proper level of fidelity. While power electronics and power management systems can have switching frequencies above the $10 \mathrm{kHz}$ range, there is a timescale tradeoff with model fidelity. The emphasis should be to develop tools that enable modeling of the electrical system to the proper level of fidelity. This includes modeling of control actuators and sensors plus capturing the system response to transient changes in electrically driven propulsors, dynamic balancing of electrical loads, and the dynamic coupling between engines and the electrical system. As with gas turbine models, these models should capture electrical system performance not only at the system design point, but at "off-design" transient operation as well, spanning the operating envelope that the system will be required to function within. The modeling of thermal loads over a mission is also important, as such information can be used to optimize the design of thermal management systems. Functional operating limits of the system should also be included so that control protection logic can be incorporated to restrict operation to appropriate regions.

\section{EAP CONTROL STRATEGIES}

EAP systems will present a number of control design challenges due to their complexity and integrated coupling. However, they are also expected to enable exciting new opportunities when it comes to controls. The need for integrated control design approaches is anticipated, with an emphasis on coordinated turbine and electrical system operation to optimize efficiency and operability, while minimizing thermal management challenges. Potential EAP control strategies are further discussed in the subsections below.

\section{Optimal Energy Management}

Focused on hybrid designs that combine output power from gas turbine engines and energy storage devices such as batteries, energy management refers to the integrated control task of scheduling how power is drawn from all available sources to supply the demanded power. For optimal efficiency throughout a mission, the scheduling of this engine/energy storage device power split should be done to minimize fuel burn while adhering to operating constraints. Optimal energy management approaches are applied within the automotive industry to define the power schedules implemented within the engine control systems of hybrid automobiles [20]. This is done by seeking to minimize a defined performance index, $J$, representative of the total fuel consumed during a reference mission of time $T$. Such a performance index can be calculated based on the integration of a defined cost function, $L(\cdot)$, as shown in the equation below [20]:

$$
J=\int_{0}^{T} L(t, u(t)) d t
$$

Here, $u(t)$ is the control vector provided by the supervisory controller. The cost function $L(\cdot)$ reflects instantaneous fuel flow rate plus any penalties incurred for violation of operating constraints. These can be hard or soft constraints and can include a variety of factors such as engine and electrical system operating limits, battery charge/discharge rates and state-of-charge limits, noise, emission, and thermal considerations. If desired, Eq. (1) can be adapted to achieve goals beyond minimizing fuel consumption. This may include minimizing total energy consumption, mission cost, or other metrics of interest.

To illustrate the application of energy management strategies to aircraft hybrid electric propulsion designs, consider the notional specific fuel consumption (SFC) versus power output curve of a turboshaft engine at a given flight condition as shown in Figure 5. The green star denotes minimum or optimal SFC, which is the engine's most efficient operating point. Typically, an engine is designed to operate close to this "design point" for a significant portion of its intended mission. Additional power settings of interest, which constrain available engine power output, are also shown. This includes:

- Idle: Minimum permitted power setting. 
- Maximum Continuous Power (MCP): Maximum amount of power that the engine can continuously provide without any time restrictions.

- Maximum Power (MP): The maximum power output that the engine can provide for a finite amount of time (e.g., 5 minutes).

- Contingency Power (CP): More common in two-engine helicopters, $\mathrm{CP}$ is a high power setting that an engine may provide for a short time (e.g., 2.5 minutes) during contingency events such as the opposite engine becoming inoperative.

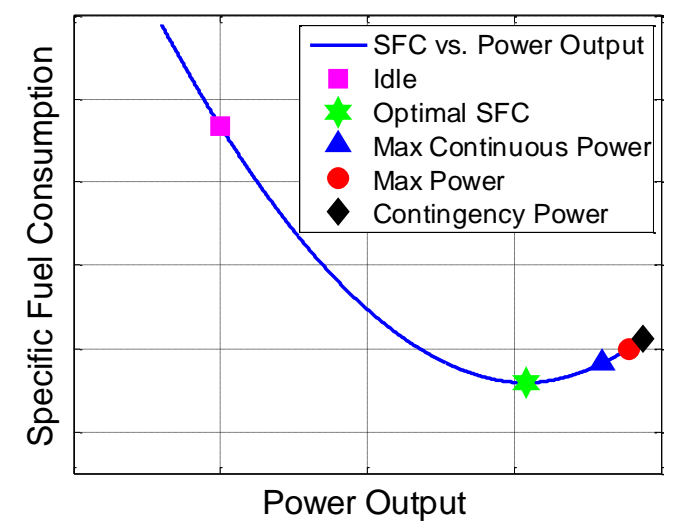

Figure 5. Notional turboshaft SFC vs. power output curve

From a fuel efficiency standpoint, the ideal case is to always run the engine at its minimum SFC operating point. But this is not possible in conventional propulsion designs as the requested propulsive power from the aircraft varies throughout a flight. However, a paradigm shift occurs when considering hybrid propulsion designs that include energy storage devices. In such architectures, it might be possible to run the gas turbine at its most efficient operating point for extended periods of time while using any excess engine power for battery charging and drawing power from the battery when the requested power exceeds that which can be supplied by the gas turbine alone. Considering a hybrid architecture that permits a battery to be both discharged and recharged during flight, there are four possible system operating modes:

1) Engine off, Battery discharging

2) Engine on, Battery charging

3) Engine on, Battery energy level is static (neither charging or discharging)

4) Engine on, Battery discharging

Given these operating modes, a simplified hybrid EAP control schedule is shown in Figure 6. Here, instantaneous power generated is shown versus instantaneous propulsive power demanded. The dashed red vertical lines denote transition points in the control schedule where switching between the four operating modes described above occurs. During regions of low power demand such as ground taxi, the engine is turned off and the battery supplies all demanded power (mode 1). When high levels of power are demanded, perhaps during takeoff or hover operations, both the engine and the battery are called upon to supply the required power (mode 4). Those instances when the power demand is less than the engine's optimal SFC power setting provide an opportunity to run the engine at its optimal SFC setting while using any excess engine generated power to recharge the battery (mode 2). As losses occur during the mechanical to electrical power conversion process, not all of the engine generated power can be converted into battery energy in mode 2 . The range in power demand transitioning between the optimal SFC power setting up to the power setting that marks the start of mode 4 reflects a region of engine-only power generation with no battery charging or discharging occurring (mode 3 ).

There are several aspects of a hybrid EAP control schedule worth noting. First, having the mode 3 region as shown in Figure 6 may only be practical for those engines where the optimal SFC power setting resides to the left of the MCP setting as for the example curve shown in Figure 5. For engines where optimal SFC resides at or above MCP, it may make sense to omit mode 3 entirely and simply transition directly from mode 2 to mode 4 . Also, the transition between modes might be dependent on phase of flight or battery state of charge. While newer automobiles apply "start-stop" technology that shuts off their engine at stoplights to save gas, it is unclear whether similar technology could ever be certified for application to aircraft engines inflight. As, such it may only be practical to operate in all electric mode (mode 1) during taxi operations at the airport. Additionally, if a battery ever reaches its fully charged state, the control is forced to transition out of battery charging (mode 2) and into one of the other modes, regardless of whether excess engine power is available. If such constraints are encountered, it will be necessary for the engine to operate off of its maximum efficiency point.

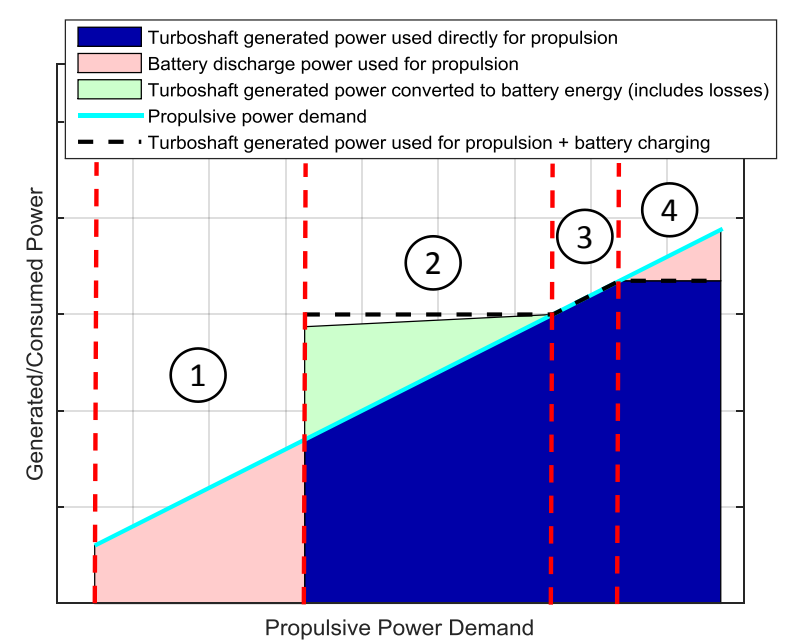

Figure 6. Notional hybrid EAP power control schedule

\section{Thermal Management}

EAP system developers face significant thermal management design challenges [4]. The need for increased levels of energy and power supplied by smaller and lighter components 
are factors contributing to increased thermal loads. Advances in high temperature materials, the development of more efficient components, and innovations in passive and active thermal management systems are needed to effectively withstand and dissipate thermal loads. EAP supervisory controllers tasked with coordinating the operation of the engine and power systems will play a key role in addressing thermal management issues. This includes scheduling engine and electrical system operation under varying levels of requested thrust and operating conditions. In conventional aircraft engine control designs, thermal challenges are partially addressed by applying a maximum rated thrust schedule as shown in Figure 7. This schedule reflects the rated or maximum thrust that the engine can produce as a function of outside air temperature at a given flight condition [21]. At this flight condition, maximum thrust is constant for outside air temperatures below the temperature value where an engine's turbine temperature limit is encountered. As outside air temperature increases beyond this value, maximum available thrust is decreased to ensure that the maximum turbine temperature limit is not exceeded. For EAP designs, analogous thrust and power scheduling logic is needed to provide temperature limit protection, although such logic is expected to be more complex and will likely involve the need to coordinate the modulation of available actuators (including engine bleed and mechanical power offtakes) to satisfy multiple temperature limits simultaneously.

In addition to implementing limits to guard against temperature exceedances, EAP engine and energy storage devices will also need to provide the power to drive any thermal management active cooling systems. This task is closely related to the optimal energy management task introduced in the previous subsection. In fact, thermal management constraints can be directly considered within Eq. (1) giving rise to a combined optimal energy and thermal management problem. Here, the objective becomes scheduling the coordinated operation of engine and energy storage devices to ensure that all thermal limits are maintained while simultaneously operating the system in the most fuel efficient manner.

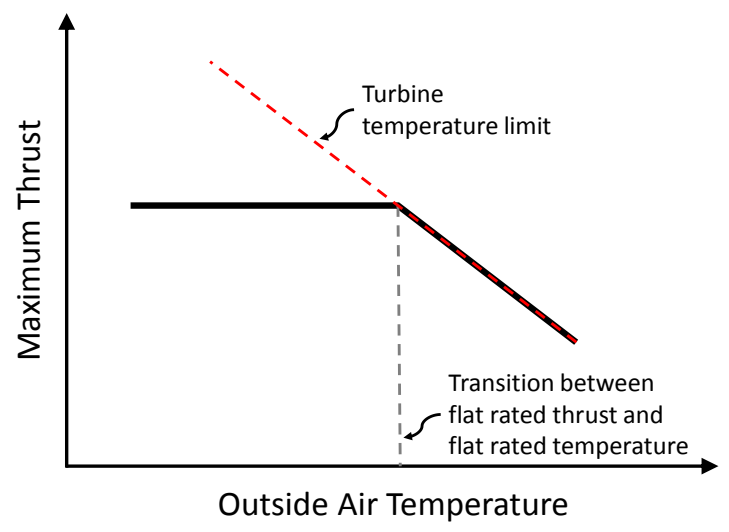

Figure 7. Engine rated thrust schedule at a fixed flight condition

\section{Transient Control Schedules and Limit Logic}

Aircraft engine control logic is responsible for ensuring the safe and reliable transient operation of the engine throughout its operating envelope [21]. This includes protection logic to guard against exceedance of engine operational, structural or safety limits. The concept of transient control is illustrated in the compressor map shown in Figure 8 [21]. Here, the solid black line represents the steady-state operating line that the engine will follow over the range of power settings. During throttle transients, engine operation will move off the steady-state operating line as denoted by the acceleration and deceleration trajectories shown in the figure. Also shown are several engine operating limits. This includes the compressor surge line, the combustor blow-out limit, and the turbine temperature limit. During transient operation, the engine controller regulates fuel flow to ensure that the engine does not exceed defined acceleration/deceleration rate schedules or defined engine operating limits.

For conventional aircraft gas turbine engines, transient control design accounts for approximately $75 \%$ of the total control law design and development effort [21]. Given their complexity and inherent coupling, EAP designs are expected to present similar transient control challenges. Protection limits are expected to be necessary to ensure the health and life of electrical components. This includes control limits placed on electric machine speed and torque levels, battery charge/discharge rates, overall power levels, and component operating temperatures. Additionally, consideration needs to be given to the dynamic coupling between the electrical system and the turbomachinery. This is especially true given the fact that the electrical system dynamic response can potentially be much more rapid than that of the turbomachinery. As such, it is likely that speed limits and over-speed protection logic will be necessary for any electric motor driven propulsors. Also, it is likely that acceleration and deceleration schedules will be needed to restrict how rapidly the electrical system can respond during transient operation to ensure both electrical and turbomachinery operability limits. As previously shown in Figure 3b, a supervisory control to ensure proper integrated coordination between the engines and the electrical power system is essential.

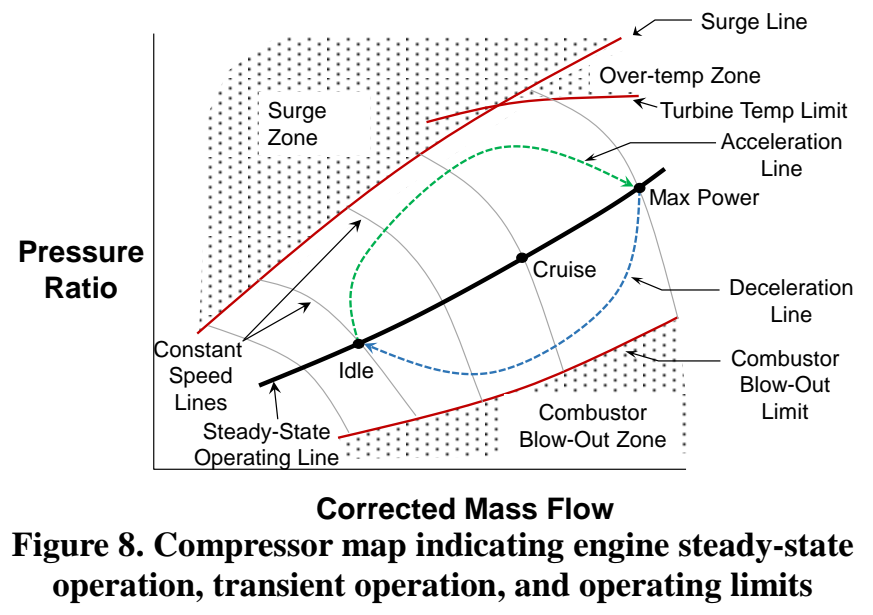




\section{Turbine Electrified Energy Management (TEEM)}

Turbine Electrified Energy Management (TEEM) is a new control technology that addresses the occurrence of off-design engine operation that occurs during changes in engine power setting or other momentary disruptions [22]. These operability issues represent potential risks to the engine that the control system traditionally mitigates by limiting the rates of change of commanded variables, such as fuel flow rate. Temporary offdesign operation is an expected natural response of the turbine engine, but it is actually a symptom of an energy imbalance between rotating components of the engine that occurs during transient operation. Inertial energy stored in the rotating components and heat energy soaked into the mass of the engine contribute to this energy imbalance.

The TEEM technology focuses on counteracting the energy imbalance inherent in gas turbine engines during transients through the use of electric machines applied to add/extract mechanical power to/from the shafts of the engine. This enables the engine to operate close to its on-design condition during transients. Applying TEEM, the rotational velocities of engine components are matched to the flow conditions in the gas path, as estimated by the commanded fuel flow rate. This allows the flow incidence angle to match the design point incidence at a particular power setting. In theory, by matching the rotational speeds of the shafts with the instantaneous fuel flow rate that defines an engine flow condition, it is possible to maintain the steady-state operating line of the turbomachinery components, particularly the compressors. This is possible, even during transient maneuvers such as a change in power setting. The steady-state operating line is generally the most efficient operating condition for that component.

One potential implementation of TEEM is shown in the architecture given in Figure 9. Here, electric machines are coupled to the rotating shafts of the turbine engine. Drawing power from an energy storage device, the electric machines are used to implement shaft speed control during the momentary periods where the shaft responses would naturally lag behind commanded fuel flow rate due to their high moments of inertia. In addition to supplying mechanical shaft power, the electric machines connected to the engine are also able to extract shaft power that is converted to electricity and used to charge energy storage devices or drive other electric machines on the vehicle. Figure 10 illustrates the typical dynamic behavior that is observed for a dual spool engine during acceleration and deceleration transients and the notional steady-state relationship that is to be maintained by TEEM for the low spool speed (N1), high spool speed (N2), and fuel flow rate (Wf). The objective is not necessarily to match the shaft speed to the design point but to maintain acceptable levels of stall margin during the transient condition. Generally, this requires a high impulsive power, but ideally it is not beyond the rating of the electric machine for its original design purpose. In terms of energy storage capacity to drive the machine, it is modest due to the short duration of the transient.

The overall effect of TEEM is to reduce the amount of transient stall margin required in the compressor system.
Reducing the amount of margin implies that engine design can be safely modified to achieve a number of benefits affecting performance and efficiency metrics. Those benefits generally appear in the form of weight and volume reduction such as the elimination of compressor stages or elimination of stability bleed valves. It may also enable reduced off-incidence flow in compressor blades leading to improvements in blade design for lower loss operation. Finally, optimizing the transient operability of the turbine engine may impact electrified propulsion system design by fully utilizing the engine as the most efficient means of converting fuel into power, thus minimizing the need for energy storage, which currently has a high weight penalty.

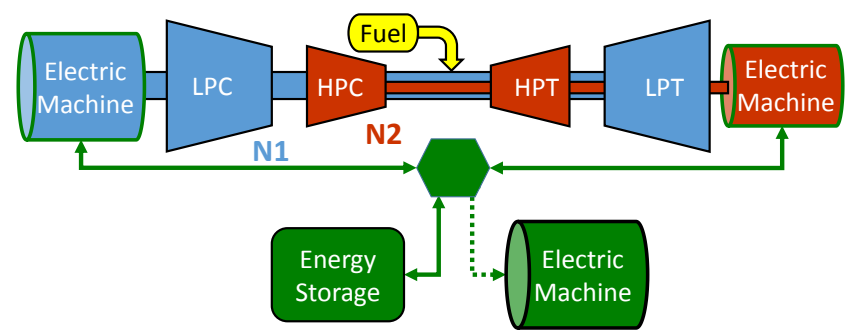

Figure 9. TEEM architecture
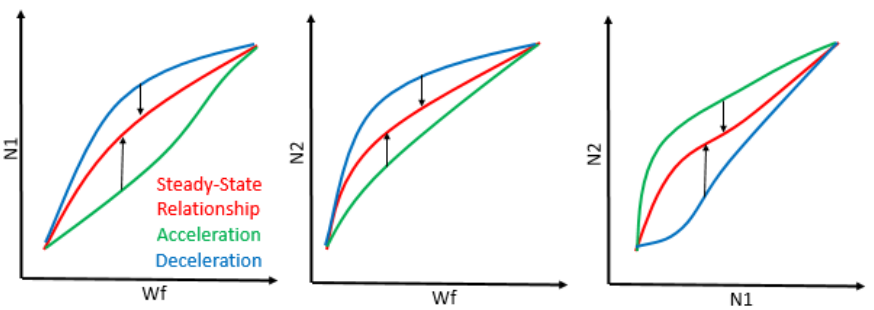

Figure 10. Schematic of the N1/N2/Wf relationship during steady-state and acceleration/deceleration transients. The black arrows indicate the desire to modify the shaft speeds during transients to operate closer to the steady-state operating line.

\section{Novel Cycle and More Electric Engine Controls}

Compared to conventional aircraft engines in service today, the gas turbine engines included in EAP systems are expected to have fundamental differences, both in their design and control. In addition to providing propulsive thrust, today's conventional aircraft gas turbine engines also supply bleed air for the aircraft's environmental control system (ECS) and mechanical power offtake to generate electricity for the aircraft. However, the engine power extracted for these functions is only a small fraction of the total power output of the engine. Conversely, some EAP designs will extract substantially higher percentages of overall engine power. This is expected to necessitate the need for novel engine cycle designs, such as variable fan and variable core nozzles to provide stability margin when electric power is extracted or applied to engine shafts [23]. With these variable cycle engines will come the need to apply control strategies to schedule operation of the engine and its variable geometry in concert with the power extraction/addition demands placed upon it [24]. 
Within the aviation industry there is an ongoing trend to transition to more electric engine (MEE) designs [25,26]. This replaces aircraft engine mechanical and pneumatic driven accessories with electrical-mechanical actuators. This includes apparatus such as accessory gear box-driven fuel and oil pumps, engine bleed off-takes for heat exchangers, ECS, and anti-ice systems. Replacing these accessories with electrically-driven systems will help to reduce weight and improve overall engine efficiency. A primary advantage of electrically actuated systems is that their operation can be scheduled in accordance to the required demand as opposed to today's gearbox driven systems that must operate at the speed dictated by the rotation of the engine. This results in the need for bypass circuits to absorb excess flow, which is inefficient. MEE designs also seek to replace pneumatic or fluid driven actuators with electricalmechanical designs. The readily available source of electricity offered by EAP systems is expected to further accelerate the transition to MEE designs in the future. With this will come the associated control design needs to optimally schedule the operation of the electrical-mechanical actuators and systems inherent in these designs.

\section{Integrated Flight and Propulsion Control}

Unlike conventional flight control strategies, which primarily view the engine as an actuator for adjusting thrust, Integrated Flight and Propulsion Control (IFPC) considers control of the vehicle and its propulsion system in a coordinated fashion. This includes modulation of engine thrust output to perform vehicle flight control functions. IFPC has been applied in short takeoff and vertical landing aircraft applications [27,28]. The feasibility of performing flight control of multi-engine fixed-wing aircraft through the modulation of engine throttles was also demonstrated under the Propulsion Controlled Aircraft project led by NASA during the 1990's [29]. Given their distributed propulsion nature, EAP vehicle designs are well suited for IFPC. Coordinated modulation of the thrust output of an array of distributed propulsors strategically positioned on the aircraft allows basic flight control maneuvers such as turns, climbs, and descents to be performed. This can eliminate or reduce the size of flight control surfaces reducing overall vehicle weight and cost. IFPC development for EAP vehicles will require a combined effort between flight and propulsion controls engineers. Key control issues are to ensure that the propulsors can efficiently provide the range and dynamic response in thrust needed for flight control, while adhering to all operational limits and constraints.

\section{FACILITIES TO ENABLE EAP TEST AND MATURATION}

The development of EAP systems and components will require corresponding facilities to test and mature the technologies. This includes facilities to perform testing of megawatt-class EAP designs [30]. To help address this need, NASA created testbeds to enable testing of EAP systems and their associated technologies. Examples include the Hybrid
Electric Integrated Systems Testbed (HEIST) [31] and the NASA Electric Aircraft Testbed (NEAT) [32]. The NEAT facility, shown in Figure 11, is located at the NASA Glenn Research Center Plum Brook Station. NEAT is a reconfigurable testbed developed to enable end-to-end development and testing of full-scale electric aircraft powertrains.

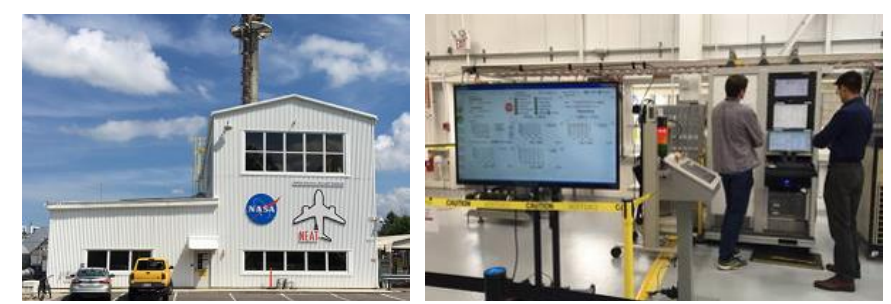

Figure 11. NASA Electric Aircraft Testbed (NEAT) facility

The focus of testing to date at NEAT is subscale testing of the powertrain of the STARC-ABL concept aircraft, a singleaisle turboelectric aircraft with an aft boundary layer propulsor [5]. A depiction of the STARC-ABL aircraft along with an overview diagram showing the STARC-ABL turbomachinery and electrical system interconnections implemented at the NEAT facility is provided in Figure 12. STARC-ABL consists of two wing-mounted turbofan engines and a tail fan propulsor driven by electric motors. Pilot power lever angle (PLA) commands specify the requested thrust output from the turbofans and the tail fan. In addition to producing thrust, the two turbofan engines also supply mechanical offtake power delivered to generators to produce electricity. Alternating current $(\mathrm{AC})$ from the generators travels through rectifiers to transport the power over direct current (DC) buses. Motor controllers command inverters to deliver the commanded current at the appropriate voltage and frequency, to generate the necessary torque at the tail fan motors to achieve the desired tail fan speed. The inverter/motor controllers also provide information to the generators so that the corresponding amount of torque load from each turbofan is commanded to extract the required power.

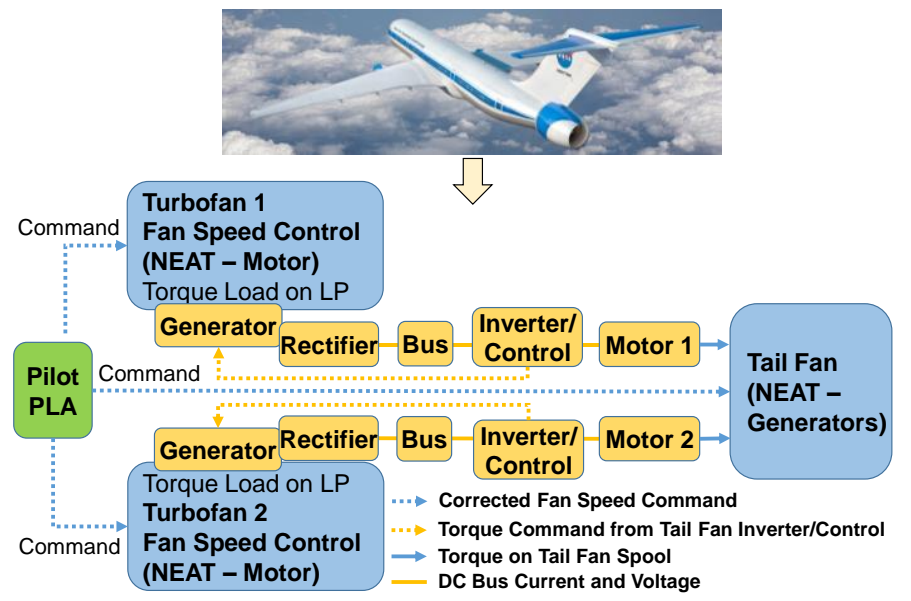

Figure 12. STARC-ABL (top) and overview diagram of

STARC-ABL turbomachinery and electrical system interconnections implemented at NEAT facility (bottom) 
In addition to serving as a testbed for powertrain technology, NEAT also provides the capability to perform real-time hardware-in-the-loop testing with emulated turbofan engines to enable initial evaluation of turbomachinery and electrical component integration challenges as well as control approaches to coordinate their operation. For the STARC-ABL configuration, this is accomplished by developing nonlinear dynamic real-time models of the turbofan engines and the tail fan. These models are developed using available turbomachinery modeling tools $[15,18]$. Prior to implementation of these realtime models at NEAT, a simple power flow model of the STARC-ABL electrical system was developed and interfaced with the turbomachinery models to create a full-system simulation. The purpose was to facilitate control studies of the propulsion system with representative electrical component models [33].

After initial development and validation, the turbomachinery models were implemented in real-time computer systems and interfaced with the STARC-ABL powertrain at NEAT. Model outputs were used to drive electric motors included in the NEAT facility to emulate the turbofan produced torque supplied to the electric generators. This enabled real-time testing of the STARC-ABL propulsion system using emulated turbomachinery and actual electrical system component hardware. A short 15 minute example flight profile consisting of a takeoff and climb phase, a cruise phase at 10,000 $\mathrm{ft}$ with a generator transient, and a descent phase was run. While much shorter than typical aircraft flight profiles, the example profile did allow evaluation of the system response throughout various phases of flight. The commanded and actual tail fan motor speed for this example flight profile is shown in Figure 13. The results indicate that the tail fan motor speed tracks the commanded value well.

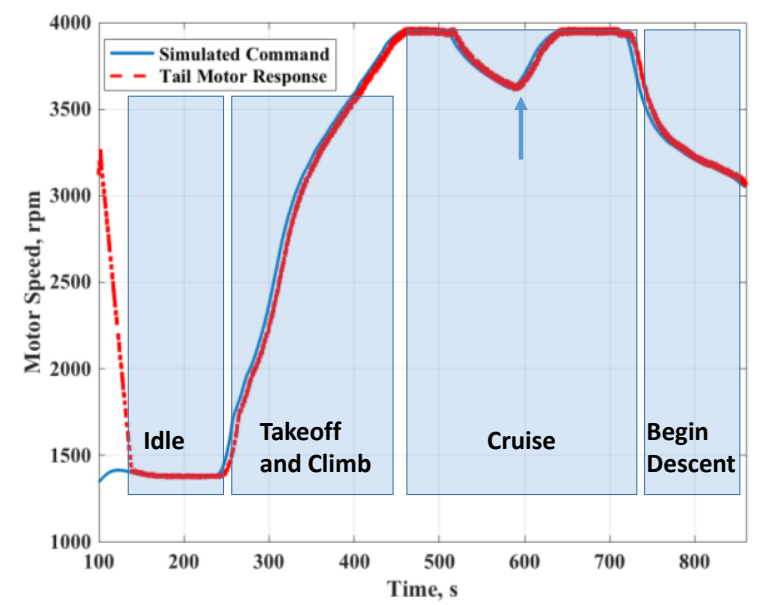

Figure 13. NEAT example flight profile tail fan spool rotational speed results with real-time turbomachinery simulation and $500 \mathrm{~kW}$ scaled powertrain hardware

NEAT and the STARC-ABL evaluation described above is just one example of the required EAP test facilities and the type of controls development testing that can occur in these facilities.
Test facilities are also needed to test EAP electrical components and full-scale EAP designs, including the control and operation of these systems in flight test environments.

\section{CERTIFICATION CONSIDERATIONS REGARDING EAP CONTROL DESIGN}

Established aerospace practices define guidelines for the development of civil aircraft and systems [34] and for conducting safety assessments on these systems [35]. This includes guidelines for onboard electronic hardware and software, such as that included in control systems [36,37,38]. Starting with an initial concept, the development process of an aircraft/system readies the concept for implementation [34]. The aircraft development process includes defining aircraft functions, allocating those functions to aircraft systems, developing the system architecture, applying requirements, and system implementation. As these development steps are conducted, several additional processes integral to ensuring system safety, requirements validation, and process assurance are happening concurrently in a coordinated, iterative fashion. This includes a system safety assessment that consists of a functional hazard assessment (FHA) conducted to identify all potential failure conditions of each function, and classify those failures according to the severity of their effects on the aircraft or its occupants. The more severe a function's failure condition classification, the greater the development assurance level (DAL) required for the function.

Typical engine functions considered during the system development and safety assessment process may include thrust modulation, thrust reverser control, communication of engine health and status information to the aircraft, and containment of engine failures to ensure passenger safety. A combination of protective strategies are applied to ensure that engine functions have safety levels in accordance with their DAL requirements. These strategies may include defined maintenance and overhaul schedules, containment systems to prevent uncontained failures, over-speed protection logic, and fail-safe design concepts leveraging system redundancy. The engine control system plays a significant role in assuring engine fail-safe operation. Typically, the EEC is a redundant dual-channel design with builtin-test and monitoring capability for potential faults in processors, sensors, or actuators. In the event of a system fault, logic within the EEC is designed to automatically detect and mitigate the anomaly. Mitigation actions may include reverting to physically redundant controls hardware, commanding actuators to failsafe positions, or reverting to reversionary control modes that allow the engine to function safely, although perhaps at a reduced performance level.

Today, aircraft engines and their control systems receive type certificate approval as a stand-alone system to signify their airworthiness. However, the complex coupling and distributed nature of EAP designs are expected to place added challenges on the certification of these systems. FHA's are needed to identify and assign DAL's to all propulsion system functions. It is expected that redundancy within the EAP architecture will be required to assure that the propulsion system can still deliver 
propulsive thrust or torque in the event of a failure. As with conventional engine designs, the EAP control system is expected to play a significant role in assuring that EAP systems comply with the airworthiness standards set forth by regulatory agencies. This includes fault detection and mitigation logic, reversionary control modes, and contingency control modes to respond to EAP system faults. The reconfiguration flexibility of EAP architectures may allow multiple acceptable control mitigation responses for an individual fault, thus enabling optimal control reconfiguration based on current mission objectives. Additionally, as with conventional engine EEC designs, the application of Time-Limited-Dispatch (TLD) concepts for EAP control systems is anticipated. TLD is a concept where a redundant system is allowed to operate for a predetermined length of time with faults present in the elements of a redundant companion system, before repairs are required [39]. This requires appropriate fault detection and fail-safe mitigation logic to be included in the EAP control system.

Other propulsion-related functions that must be considered during the development of aircraft equipped with EAP are the propulsion flight deck controls and displays. In conventional designs, individual throttle levers and cockpit gauges are available for each engine. For EAP designs with multiple distributed propulsors, flight crew control and monitoring of each individual propulsor may be untenable and increase the likelihood of human error. Therefore, considerations must be given to the format in which thrust commands are delivered to the EAP system and then distributed to multiple propulsors

\section{REFERENCES}

[1] Jansen, R.H., Bowman, C., Jankovsky, A., Dyson, R., Felder, J., (2017), "Overview of NASA Electrified Aircraft Propulsion Research for Large Subsonic Transports," AIAA-2017-4701, AIAA Propulsion and Energy Forum, Atlanta, GA, July 10-12.

[2] Kim, H.D., Perry, A.T., Ansell, P.J., (2018), "Review of Distributed Electric Propulsion Concepts for Air Vehicle Technology," AIAA-2018-4998, AIAA Propulsion and Energy Forum, Cincinnati, OH, July 9-11.

[3] Felder, J.L., (2015), "NASA Electric Propulsion System Studies," presentation, 5th EnergyTech 2015, Cleveland, OH, Nov. 30 - Dec 2.

[4] National Academies of Sciences, Engineering, and Medicine. 2016. Commercial Aircraft Propulsion and Energy Systems Research: Reducing Global Carbon Emissions. Washington, DC: The National Academies Press. https://doi.org/10.17226/23490.

[5] "NASA Aeronautics Strategic Implementation Plan 2017 Update," National Aeronautics and Space Administration, (2017), https://www.nasa.gov/sites/default/files/atoms/files/ sip2017-03-23-17-high.pdf [retrieved 19 September 2018].

[6] Borer, N.K., Derlaga, J.M., Deere, K.A., Carter, M.B., Viken, S.A., Patterson, M.D., Litherland, B.L., Stoll, A.M., (2017), "Comparison of Aero-Propulsive Performance installed on the aircraft as well as how EAP health and status information is conveyed back to the flight crew.

\section{SUMMARY}

Electrified aircraft propulsion systems hold potential for reducing aircraft emissions, noise, and fuel burn. Several technology barriers must be addressed to bring these designs to fruition, including development of the controls technology required for EAP. Given their complexity, distributed nature, and the inherent coupling between turbomachinery and electrical systems, EAP system control designs are expected to provide new challenges. This paper discussed several control technology needs to enable EAP. These include modeling tools for creating integrated turbine and electrical system models for control design and evaluation, control architectures and control strategies for EAP systems, test facilities for the development of EAP systems and controls, and fault detection and mitigation functions included within control logic to enable EAP certification. Development of the control technologies necessary for EAP systems will require a concerted effort by NASA and the aerospace community.

\section{ACKNOWLEDGMENTS}

This work was conducted under the NASA Advanced Air Vehicles Program, Advanced Air Transport Technology Project. The authors wish to thank members of the Commercial AeroPropulsion Controls Working Group for their feedback on the EAP control needs captured in this document.

Predictions for Distributed Propulsion Configurations," AIAA 2017-0209, AIAA SciTech Forum, 55 ${ }^{\text {th }}$ AIAA Aerospace Sciences Meeting, Grapevine, TX, Jan 9-13.

[7] Welstead, J.R., Felder, J.L., (2016), "Conceptual Design of a Single-Aisle Turboelectric Commercial Transport with Fuselage Boundary Layer Ingestion," AIAA 2016-1027, AIAA SciTech Forum, 54th AIAA Aerospace Sciences Meeting, San Diego, CA, January 4-8.

[8] Kim, H.D., Felder, J.L., Tong, M.T., Armstrong, M., (2013), "Revolutionary Aeropropulsion Concept for Sustainable Aviation: Turboelectric Distributed Propulsion,” ISABE-2013-1719, 21st International Society for Air Breathing Engines, Busan, Korea, September 9-13.

[9] Johnson, W., Silva, C., Solis, E., (2018), "Concept Vehicles for VTOL Air Taxi Operations," AHS Technical Conference on Aeromechanics Design for Transformative Vertical Flight, San Francisco, CA, January 16-19.

[10] Silva, C., Johnson, W., Antcliff, K.R., Patterson, M.D., (2018), "VTOL Urban Air Mobility Concept Vehicles for Technology Development," AIAA 2018-3847, 2018 Aviation Technology, Integration, and Operations Conf., AIAA Aviation Forum, Atlanta, GA, June 25-29.

[11] Bruno, M., "Aerospace Sector Could See Overhaul From Electric Propulsion," Aviation Week \& Space Technology, p. 28, August 24, 2018. 
[12] Warwick, G., Osborne, T., (2017), "Airbus E-Fan X To Pave Way For Electric Regional Aircraft," Aviation Week \& Space Technology, December 1, 2017.

[13] Warick, G., "Boeing-Backed Zunum's First Aircraft To Be 12-seat Commuter," Aviation Week \& Space Technology, p. 22, October 5, 2017.

[14] Adibhatla, S., Ding, J., Garg, S., Griffith, S., Karnofski, K., Payne, N., Simon, D., Wood, B., (2018), "Propulsion Control Technology Development Needs to Address NASA Aeronautics Research Mission Goals for Thrusts 3a and 4," AIAA-2018-4824, AIAA Propulsion and Energy Forum, Cincinnati, OH, July 9-18.

[15] Lytle, J., Follen, G., Naiman, C., Evans, A., Veres, J., Owen, K., Lopez, I., (2000), "Numerical Propulsion System Simulation (NPSS) 1999 Industry Review," NASA/TM-2000-209795, August.

[16] Kurzke, J., (2007), "GasTurb 11 Design and Off-Design Performance of Gas Turbines," Dachau, Germany.

[17] Bala, A., Sethi, V., Lo Gatto, E., Pachidis, V., Pilidis, P., "PROOSIS - A Collaborative Venture for Gas Turbine Performance Simulation using an Object Oriented Programming Schema," ISABE-2007-1357, Proceedings XVIII International Symposium on Air Breathing Engines (ISABE), Beijing, China, September 2-7.

[18] Chapman, J.W., Lavelle, T.M., May, R.D., Litt, J.S., Guo, T-H., (2014), "Toolbox for the Modeling and Analysis of Thermodynamic Systems (T-MATS) User's Guide," NASA/TM-2014-216638, January.

[19] Armstrong, J.B., Simon, D.L., (2012), "Constructing an Efficient Self-Tuning Aircraft Engine Model for Control and Health Management Applications," 2012 Annual Conference of the Prognostics and Health Management Society, Minneapolis, MN, September 23-27.

[20] Sciarretta, A., Guzzella, L., (2007), "Control of Hybrid Electric Vehicles," IEEE Control Systems Magazine, pgs. 60-70, April, 2007.

[21] Jaw, L.C., Mattingly, J.D., (2009), Aircraft Engine Controls: Design, System Analysis and Health Monitoring, American Institute of Aeronautics and Astronautics, 1801 Alexander Bell Drive, Suite 500, Reston, VA 20191-4344, USA.

[22] Culley, D.E., Kratz, J.L., Thomas, G.L., (2018), “Turbine Electrified Energy Management (TEEM) For Enabling More Efficient Engine Designs," AIAA-2018-4798, AIAA Propulsion and Energy Forum, Cincinnati, OH, July 9-18.

[23] Bradley, M. K., Droney, C. K., (2015), "Subsonic Ultra Green Aircraft Research: Phase II - Volume II - Hybrid Electric Design Exploration,” NASA/CR-2015-218704, April.

[24] Thomas, G.L., Culley, D.E., Kratz, J.L., Fisher, K.L., (2018), "Dynamic Analysis of the hFan, a Parallel Hybrid Electric Turbofan Engine," AIAA-2018-4797, AIAA2018-4798, AIAA Propulsion and Energy Forum, Cincinnati, OH, July 9-18.

[25] Provost, M.J., (2002), "The More Electric Aero-engine: A General Overview from an Engine Manufacturer,” 2002
International Conference on Power Electronics, Machines and Drives (Conf. Publ. No. 487), June.

[26] Morioka, N., Oyori, H., Kakiuchi, D., Ozawa, K., (2011), "More Electric Engine Architecture for Aircraft Engine Application," ASME-GT2011-46765, Proceedings of ASME Turbo Expo 2011, Vancouver, Canada, June 6-10.

[27] Garg, S., (1993), "Robust Integrated Flight/Propulsion Control Design for a STOVL Aircraft using $\mathrm{H}$-infinity Control Design Techniques," Automatica, Volume 29, Issue 1, January, pp. 129-145.

[28] Aouf, N., Bates, D.G., Postlethwaite, I., Boulet, B., (2002), "Scheduling Schemes for an Integrated Flight and Propulsion Control System," Control Engineering Practice, Volume 10, Issue 7, July, pp. 685-696.

[29] Burken, J.J., Burcham, F.W., (1997) "Flight-Test Results of Propulsion-Only Emergency Control System on MD-11 Airplane," Journal of Guidance, Control, and Dynamics, Vol. 20, No. 5, pp. 980-987.

[30] Thole, K., Whitlow, W. \& et al., "Commercial Aircraft Propulsion and Energy Systems Research: Reducing Global Carbon Emissions," The National Academies Press, 2016.

[31] Papathakis, K.V., Kloesel, K. J., Lin, Y., Clarke, S., Ediger, J.J., Ginn, S., (2016), "Design and Development of a 200kW Turboelectric Distributed Propulsion Testbed," AIAA2016-4611, AIAA Propulsion and Energy Forum, Salt Lake City, UT, July 25-27.

[32] Dyson, R., "NASA Electric Aircraft Testbed (NEAT) Single-Aisle Transport Air Vehicle Hybrid Electric TailCone Thruster Powertrain Configuration and Test Results," AIAA 2018-5004, 2018. Doi. 10.2514/6.2018-5004.

[33] Connolly, J, Chapman, J., Stalcup, E. Chicatelli, A., Hunker, K., and Thomas, G., (2018), "Modeling and Control Design for a Turboelectric Single Aisle Aircraft Propulsion System," AIAA 2018-5010. AIAA Propulsion and Energy Forum, Cincinnati, OH, July 9-18.

[34] SAE International Aerospace Recommended Practice, (2010), "Guidelines for Development of Civil Aircraft and Systems," SAE Standard ARP4754A, December 2010.

[35] SAE International Aerospace Recommended Practice, (1996), "Guidelines and Methods for Conducting the Safety Assessment Process on Civil Airborne Systems and Equipment," SAE Standard ARP4761, December 1996.

[36] RTCA DO-297, (2005), "Integrated Modular Avionics (IMA) Development Guidance and Certification Considerations," RTCA, Inc., November 2005.

[37] RTCA DO-254, (2000), "Design Assurance Guidance for Airborne Electronic Hardware," RTCA, Inc., April 2000.

[38] RTCA DO-178C, (2012), "Software Considerations in Airborne Systems and Equipment Certification," RTCA, Inc., April 2012.

[39] SAE International Aerospace Recommended Practice, (2018), "Guidelines for Time-Limited-Dispatch (TLD) Analysis for Electronic Engine Control Systems," SAE Standard ARP5107C, September 2018. 